\title{
TENSILE BEHAVIOUR OF MULTI-PLY STEEL- REINFORCED GROUT (SRG) COMPOSITES
}

\author{
Sultan S. Alotaibi ${ }^{1,2}$, Georgia E. Thermou ${ }^{3}$, Iman Hajirasouliha $^{4}$, Maurizio Guadagnini ${ }^{4}$ \\ ${ }^{1} \mathrm{PhD}$ student, The University of Sheffield, Civil and Structural Engineering Department, Sir \\ Frederick Mappin Building Mappin Street, Sheffield, S1 3JD, UK \\ ${ }^{2}$ Shaqra University, Civil Engineering Department, 17441, Al Duwadimi, Saudi Arabia; \\ ssalotaibi1@sheffield.ac.uk \\ ${ }^{3}$ Assistant Professor, University of Nottingham, Civil Engineering Department, B76 Coates Building, \\ Nottingham, NG7 2RD, UK \\ ${ }^{4}$ Senior lecturer, The University of Sheffield, Civil and Structural Engineering Department, Sir \\ Frederick Mappin Building Mappin Street, Sheffield, S1 3JD, UK
}

\begin{abstract}
Steel Reinforced Grout (SRG) composites consist of Ultra High Tensile Strength Steel (UHTSS) fabrics embedded in an inorganic mortar matrix. The use of SRG for the repair and retrofitting of deficient structures has emerged as a novel technique in the last few years. This paper discusses the results of a comprehensive experimental study on the tensile behaviour of multiply SRG composites. A total of 24 direct tensile tests were conducted on SRG coupons to assess the influence of the fabric's layout and architecture on cracking and overall tensile behaviour. Two main parameters were investigated, including the number of fabric layers (1, 2, and 3 layers) and the density of the steel fabric (4 and 8 cords/in). It was found that, although the grout contribution is significant up until failure regardless of the number of layers, the ultimate strength of the composite is generally governed by the ultimate strength of the fabric. The large amount of densely distributed cracks that developed throughout the length of the coupons suggests that a good bond could develop between the fabric and the grout, possibly as a result of the geometry of the twisted cords and the development of good mechanical interlock.
\end{abstract}

Keywords: Composite Materials; Steel-Reinforced Grout (SRG); Bond Behaviour; Seismic Retrofitting; Tensile Tests; Digital Image Correlation (DIC) 


\section{INTRODUCTION}

Different strengthening systems have been used for repair and strengthening of existing structures. Externally bonded reinforcement (EBR) system is one of the most widely used techniques as it provides significant improvement to the structural member in terms of strength, mass and stiffness. Among EBR systems are Fibre Reinforced Polymers (FRPs) which consist of textiles impregnated in epoxy-based composites. This latter system, however, was reported to have some disadvantages associated with fire performance and durability. To address these issues, an inorganic-based system has been proposed which is a composite made of textiles embedded in an inorganic matrix. This innovative system has shown many promising advantages including better material compatibility and vapour permeability, better performances at high temperatures, and lower cost and time of installation [1].

Different acronyms are used to describe this system including Textile Reinforced Mortar (TRM), Fibre Reinforced Cementitious Matrices (FRCM), and Steel Reinforced Grout (SRG). This latter acronym is exclusive for inorganic-based composites with only steel textiles while FRCM and TRM include steel or other textiles e.g. carbon. A considerable amount of literature has been published on organic-based composites (i.e. FRP) contrary to inorganic-based systems (e.g. SRG) due to the novelty of SRG system. Debonding is a common failure mode in SRG composites when used as EBR for flexural members. This establishes the fact that understanding tensile behaviour for such systems is fundamental.

For large structural members, one layer of reinforcement might not be sufficient to achieve the desired flexural capacity and hence more than one layer should be considered. This paper investigates the tensile behaviour of multiple layers of two different textiles. Twenty-four direct tensile tests have been conducted on SRG coupons. Two parameters were considered including the number of steel reinforcement layer (one, two, and three layers) and the density of cords within a textile (four and eight cords/in).

Few studies were devoted to understand tensile behaviour of SRG composite. Different parameters were considered including textile density [1, 2, 4-8], ageing [2], and matrix type [35]. It seems that the tensile behaviour of SRG system strengthened with multi-ply steel has not yet been investigated which is often required for strengthening large structural members.

\section{EXPERIMENTAL PROGRAMME}

A total of twenty-four coupons of SRG composite were manufactured (four identical coupons for each parameter of study). Coupons were cast in a mould made of acrylic glass. Each coupon was cast individually i.e. not cut out of a wider sheet of composite. Each coupon measures 600 $\mathrm{mm} \times 50 \mathrm{~mm}$. The thickness of each coupon is 6,9 , and $12 \mathrm{~mm}$ for coupons of one, two, and three layers of steel textile respectively [Figure 1a].

Two steel textiles were used in this experiment with the same mechanical properties but varying in cords density including 4 and 8 cords/in. The textile is made of unidirectional ultrahigh strength galvanized steel cords fixed to a non-structural fibre-glass mesh. Each cord is made of three straight filaments and two twisted along the other three. Each cord has an area of $0.538 \mathrm{~mm}^{2}$ and a tensile breaking load of more than $1500 \mathrm{~N}$. The equivalent thickness of the textile is approximately $0.084 \mathrm{~mm}$ and $0.169 \mathrm{~mm}$ for textiles of 4 and 8 cord/in respectively. The mechanical properties (found in the manufacturer's data sheet) for both textiles, including tensile strength, elastic modulus, and strain at failure are $2800 \mathrm{MPa}, 190 \mathrm{GPa}$, and 1.5\%, respectively. The matrix is a polymer-modified cement mortar reinforced with microfibers to enhance hydration and mitigate shrinkage [1]. The mortar was mixed using a water-to-cement ratio of $1 / 5$. 
Each coupon was cast by applying a first layer of grout with a thickness of approximately 3 $\mathrm{mm}$. Immediately after applying the first layer, the steel textile was placed on top and gently pressed to ensure a good impregnation with the grout. An additional layer of grout was applied with the same thickness as the first layer. This process was repeated for coupons with two and three layers of steel textiles. Coupons were left to cure in a mist room for the first 28 days and were then placed in a laboratory condition until the day of testing.

The coupon specimens are given the notation DT-DX-LY-Z, where DT indicates direct tensile tests, DX indicates textile density including 4 cord/in $(X=4)$ and 8 cord/in $(X=8), L Y$ indicates number of layers of steel textile including one layer $(Y=1)$, two layers $(Y=2)$, and three layers $(\mathrm{Y}=3)$, and finally $\mathrm{Z}$ is to differentiate between identical samples. Four identical coupons for each series were fabricated and tested, i.e. $Z=1,2,3$, and 4.

Coupons were tested in a universal testing machine at a loading rate of $0.01 \mathrm{~mm} / \mathrm{s}$. Tensile load was applied to the coupon by clamping both ends in between the jaws of the machine. To prevent local damage, the ends of the coupon were impregnated in a two-part epoxy and sandwiched between two aluminum plates measuring $100 \mathrm{~mm} \times 50 \mathrm{~mm}$.

The load was acquired from the load cell of the testing machine while average and local strain was derived by means of extensometers and Digital Image Correlation (DIC). The extensometer was placed on one side of the specimen to measure the relative displacement between two rods attached to the two ends of the composite [Figure 1a]. DIC speckles were painted on the front face of the coupon and images were captured during the test at 5 seconds intervals. A light source was pointed towards the front face of the coupon to achieve the right contrast. It should be noted, however, that the data acquired from DIC system is not presented in this paper. An image of the general setup is shown in Figure $1 b$.

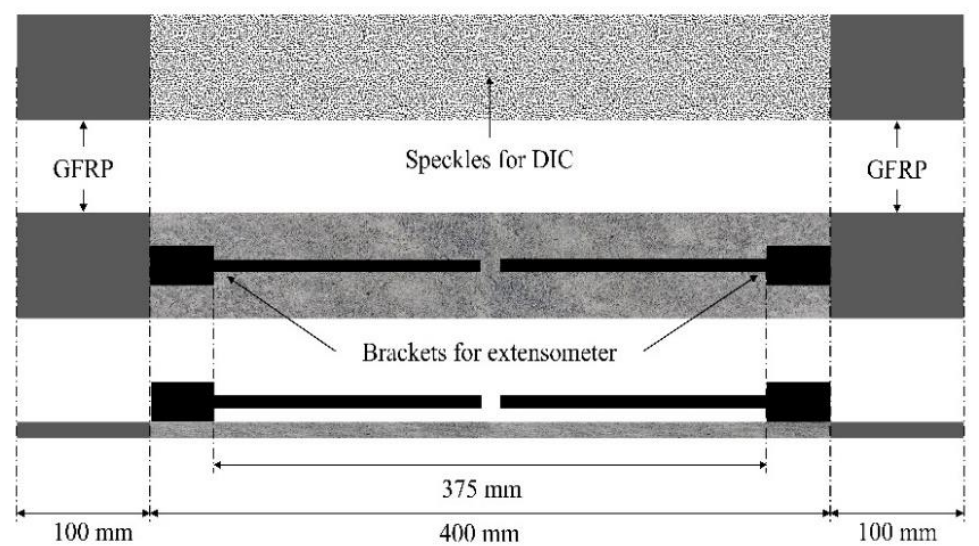

(a)

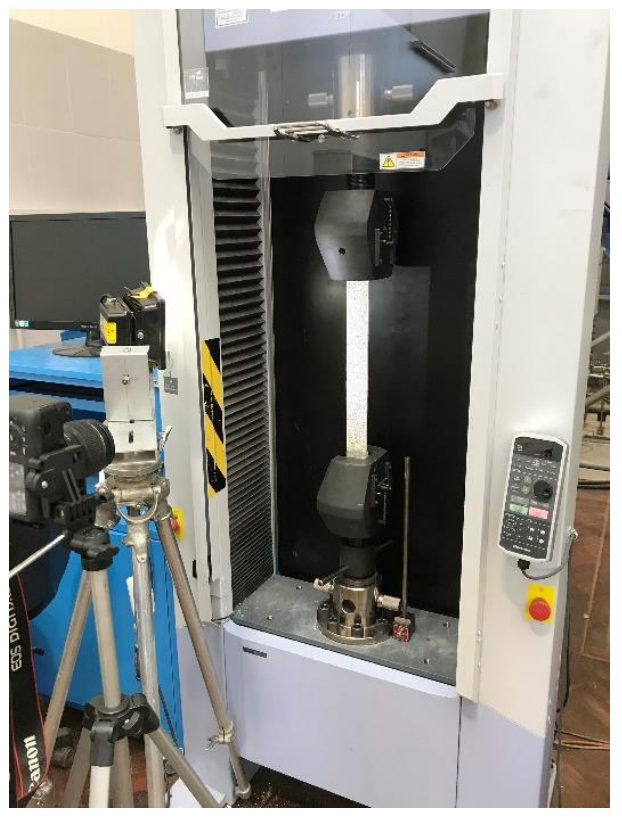

(b)

Figure 1. (a) Geometry and instrumentation of coupon (b) Test setup 


\section{RESULTS AND DISCUSSION}

The results of direct tensile tests are given in Table 1. Maximum stress, strain at maximum stress, and modulus of elasticity for Zone 3 (see below) are given in the table. The maximum stress was calculated by dividing the maximum load by the cross-sectional area of the steel cords. This latter was calculated by multiplying the cross sectional area of one cord by the total number of cords for each series. The stress-strain envelops and average curves for all series are presented in Figure 2.

Table 1: Direct tensile test results

\begin{tabular}{|c|c|c|c|c|c|}
\hline Series & Specimen & $\begin{array}{r}F_{\max } \\
(\mathbf{k N})\end{array}$ & $\begin{array}{c}\sigma_{\max } \\
(\mathrm{MPa})\end{array}$ & $\begin{array}{c}\varepsilon_{\max } \\
(\%)\end{array}$ & $\begin{array}{c}E \\
(\mathbf{G P a})\end{array}$ \\
\hline \multirow{6}{*}{ DT-D4-L1 } & DT-D4-L1-1 & 11.42 & 3032.4 & N/A & N/A \\
\hline & DT-D4-L1-2 & 8.83 & 2344.67 & N/A & N/A \\
\hline & DT-D4-L1-3 & 9.38 & 2490.71 & 1.53 & 171 \\
\hline & DT-D4-L1-4 & 11.11 & 2950.08 & 1.87 & 147 \\
\hline & Average & 10.19 & 2704.47 & 1.7 & 159 \\
\hline & CV $(\%)$ & 12.5 & 12.51 & 14.15 & 11 \\
\hline \multirow{6}{*}{ DT-D4-L2 } & DT-D4-L2-1 & 20.17 & 2677.91 & 1.7 & 146 \\
\hline & DT-D4-L2-2 & 21.43 & 2845.2 & 1.87 & 155 \\
\hline & DT-D4-L2-3 & 22.67 & 3009.83 & 2.03 & 142 \\
\hline & DT-D4-L2-4 & 20.06 & 2663.31 & 1.6 & Undetectable \\
\hline & Average & 21.09 & 2799.07 & 1.8 & 148 \\
\hline & CV $(\%)$ & 5.82 & 5.83 & 10.54 & 5 \\
\hline \multirow{6}{*}{ DT-D4-L3 } & DT-D4-L3-1 & 31.52 & 2789.88 & 1.78 & 153 \\
\hline & DT-D4-L3-2 & 32.58 & 2883.7 & N/A & 157 \\
\hline & DT-D4-L3-3 & 31.63 & 2799.62 & 1.71 & 159 \\
\hline & DT-D4-L3-4 & 41.95 & 3713.05 & 1.77 & Undetectable \\
\hline & Average & 34.42 & 3046.57 & 1.76 & 157 \\
\hline & CV $(\%)$ & 14.65 & 14.65 & 2.16 & 2 \\
\hline \multirow{6}{*}{ DT-D8-L1 } & DT-D8-L1-1 & 22.21 & 2752.17 & 1.89 & 134 \\
\hline & DT-D8-L1-2 & 14.84 & 1838.91 & N/A & Undetectable \\
\hline & DT-D8-L1-3 & 19.83 & 2457.25 & 1.58 & 156 \\
\hline & DT-D8-L1-4 & 18.61 & 2306.08 & 1.36 & Undetectable \\
\hline & Average & 18.88 & 2338.61 & 1.61 & 145 \\
\hline & CV $(\%)$ & 16.3 & 16.3 & 16.54 & 11 \\
\hline \multirow{6}{*}{ DT-D8-L2 } & DT-D8-L2-1 & 43.58 & 2700.13 & 1.88 & 144 \\
\hline & DT-D8-L2-2 & 42.1 & 2608.43 & N/A & Undetectable \\
\hline & DT-D8-L2-3 & 41.43 & 2566.92 & 1.79 & 141 \\
\hline & DT-D8-L2-4 & 43.02 & 2665.43 & 1.81 & 140 \\
\hline & Average & 42.54 & 2635.23 & 1.83 & 142 \\
\hline & CV $(\%)$ & 2.25 & 2.25 & 2.59 & 2 \\
\hline \multirow{6}{*}{ DT-D8-L3 } & DT-D8-L3-1 & 64.95 & 2682.78 & 1.78 & 152 \\
\hline & DT-D8-L3-2 & 67.81 & 2800.91 & 2.08 & 138 \\
\hline & DT-D8-L3-3 & 63.97 & 2642.3 & 1.77 & 149 \\
\hline & DT-D8-L3-4 & 64.83 & 2677.82 & 2.19 & Undetectable \\
\hline & Average & 65.39 & 2700.96 & 1.96 & 142 \\
\hline & CV $(\%)$ & 2.56 & 2.56 & 10.86 & 6 \\
\hline
\end{tabular}


Almost all specimens showed three distinct zones behaviour. Un-cracked specimen (Zone 1), cracks initiation and propagation (Zone 2) and finally crack widening (Zone 3 ). In Zone 1 the contribution of grout is dominant, while Zone 2 can be seen as a transition zone in which the stress is progressively transferred to the steel cords. In Zone 3, load is mostly resisted by the steel cords yet the grout is still contributing through tension stiffening between cracked sections. A similar three-zone behaviour is reported in [e.g. 3 and 8].

In terms of maximum stress, an ascending trend can be identified. Increasing the number of textile layers seems to slightly increase the stress that can be developed in the steel textile. An increase of approximately $3.5 \%$ and $12.6 \%$ was observed for series DT-D4-L2 (2 layers) and DT-D4-L3 (3 layers), respectively, when compared to DT-D4-L1 (1 layer). On the other hand, coupons with two and three layers of medium-density textile are characterised by an increase, in ultimate stress of $12.7 \%$ and $15.5 \%$, respectively, compared to the one-layer counterpart. A similar trend was also observed for strain, although at a lower rate.

Stress-strain diagrams clearly show that, regardless of the number of layers, the grout contribution is significant up until failure and the ultimate strength of the composite is generally governed by the ultimate strength of the textile.

The formation of large amount of evenly distributed micro cracks suggests good composite action between the steel cords and the polymer-modified matrix. This indeed indicates that good bond was developed between the fabric and the grout, largely as a result of the geometry of the twisted cords and the development of good mechanical interlock. The cracks were barely noticeable by naked eyes and could only be detected after image processing in DIC software. However, some coupons had a noticeable single crack at either top, bottom, or both ends as a result of local stresses at the clamping area [e.g. Figure 3a, 3b]. No crushing was noticed at ends thanks to the GFRP wrapping at the edges. Slippage of cords within the grout was not observed.

All tested specimens failed explosively expelling debris of grout fragments [e.g. Figure 3e], with larger amounts of energy being released for multiple layers of the denser steel textile. A quasi-simultaneous rupture of cords was observed for almost all coupons either at middle or at one end [e.g. Figure 3d, 3f]. However, early rupture of cords was observed for few coupons at a load of approximately $0.85 \mathrm{~F}_{\max }$. This can be as a result of unavoidable misalignment of the steel cords or layers during the manufacturing process.

\section{CONCLUSION}

The aim of the present study was to examine the tensile behavior of multi-ply steel-reinforced grout composites. Two parameters were investigated including steel textile density (4 and 8 cord/in) and number of textile layers (1,2, and 3). A total of 24 direct tensile tests were conducted on SRG coupons. A tensile behaviour characterised by three distinct zones was observed for almost all specimens, with the first zone being governed by the grout, the second zone corresponding to the stress being transferred to the steel cords, and finally the last zone where the steel is governing. Although the grout contribution is significant up until failure regardless of the number of layers, the ultimate strength of the composite is generally governed by the ultimate strength of the fabric. The large amount of densely distributed cracks that developed throughout the length of the coupons suggests that a good bond develops between the textile and the grout, largely as a result of the geometry of the twisted cords and the development of good mechanical interlock. It was also found that increasing the number of textile layers slightly increase the stress in the reinforcement. The coupons failed by either rupture of the cords at one end or at the middle; in both cases, however, it was nearlysimultaneous and explosive. 


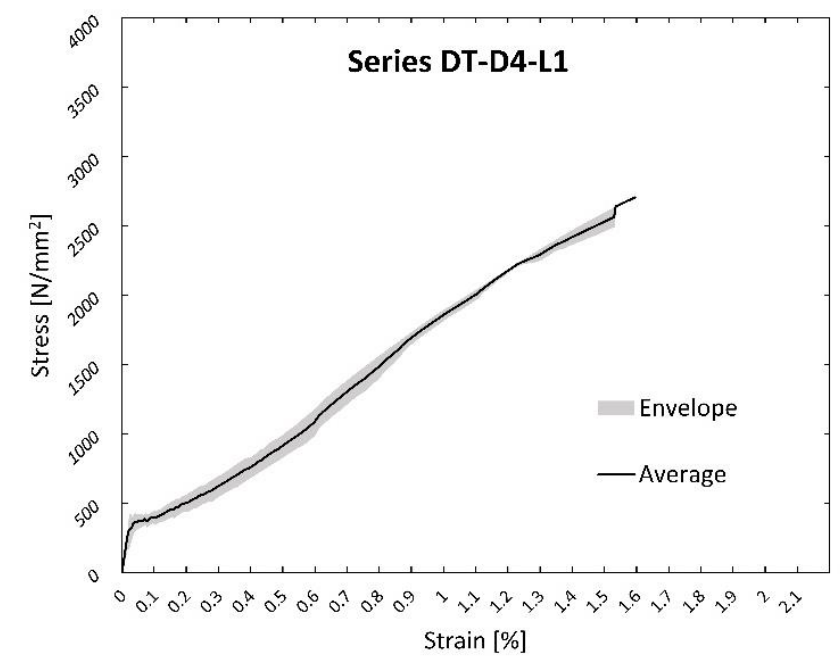

(a)

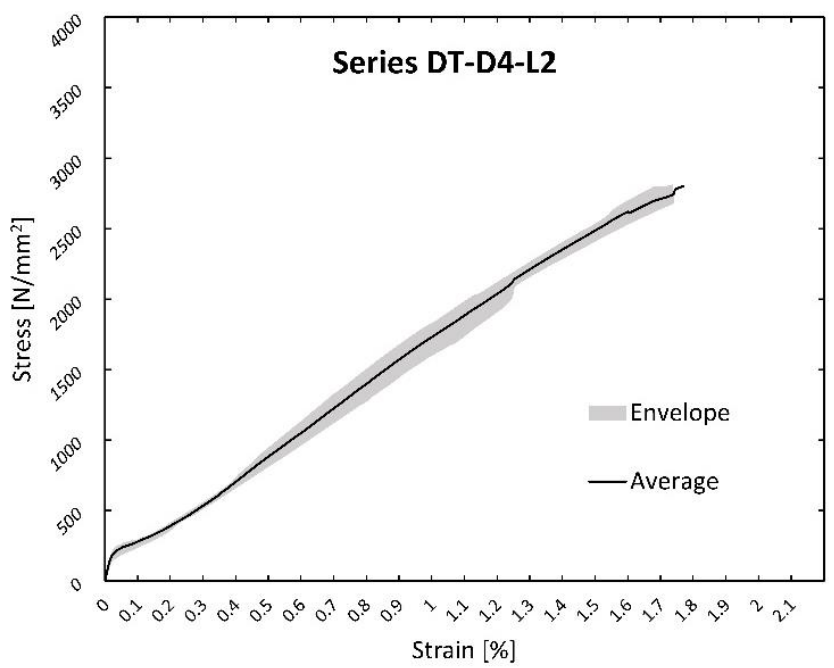

(c)

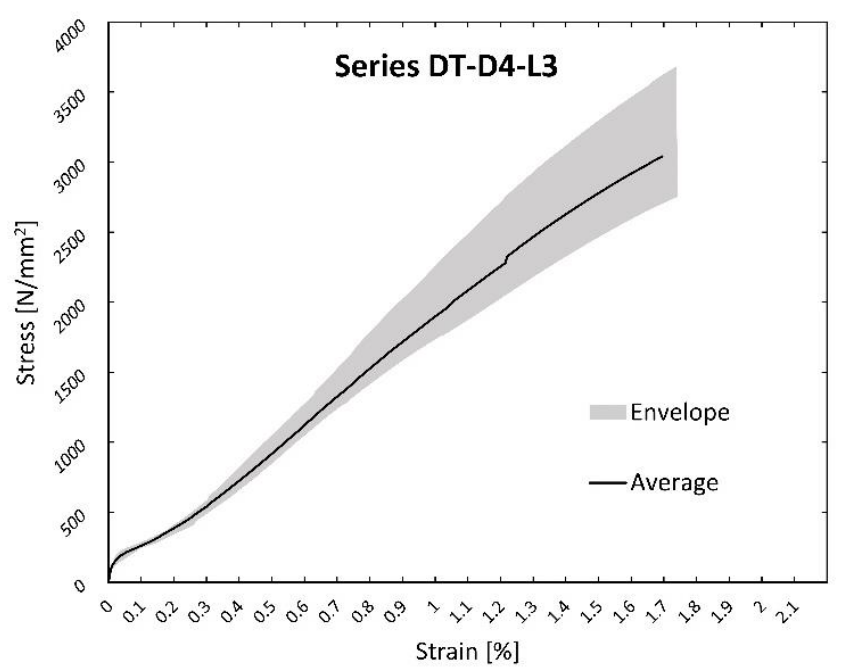

(e)

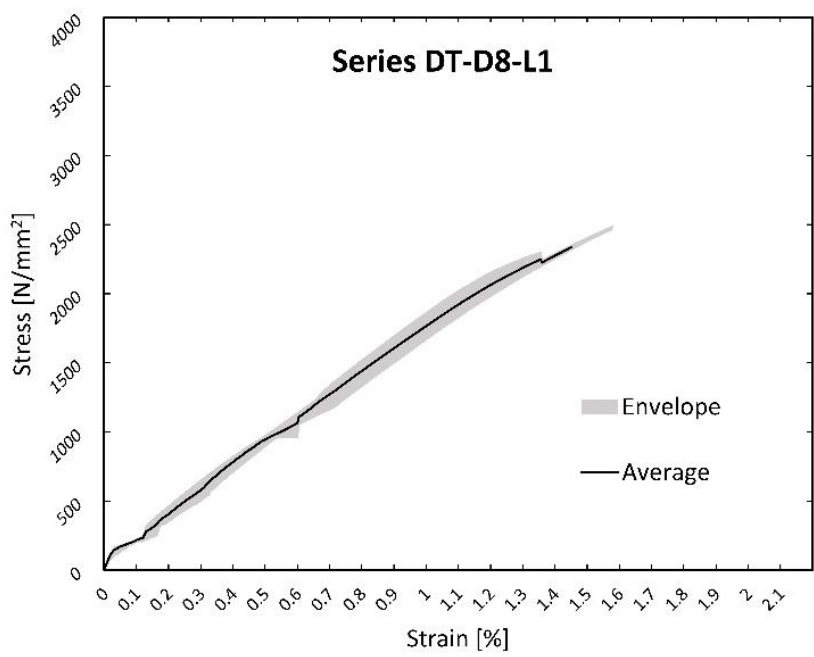

(b)

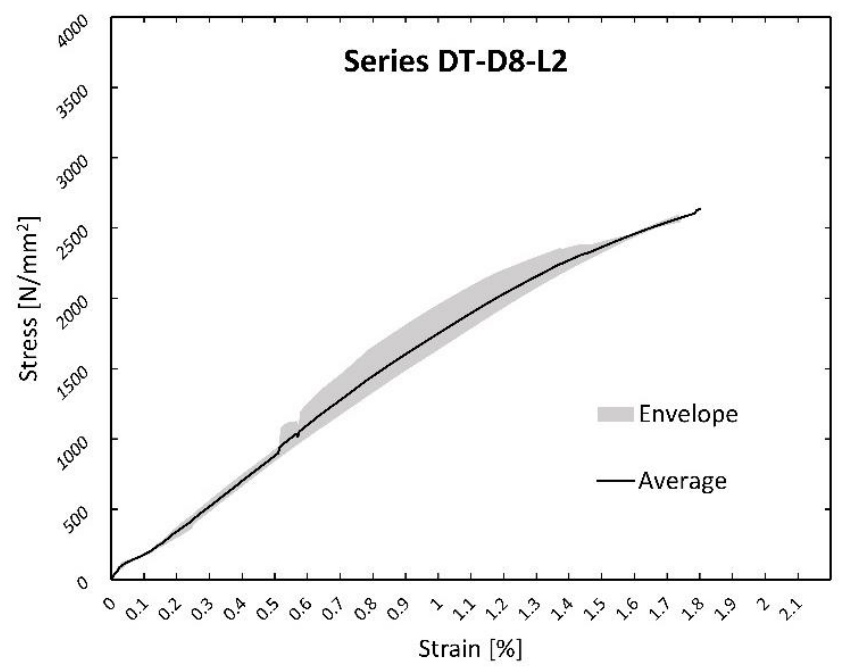

(d)

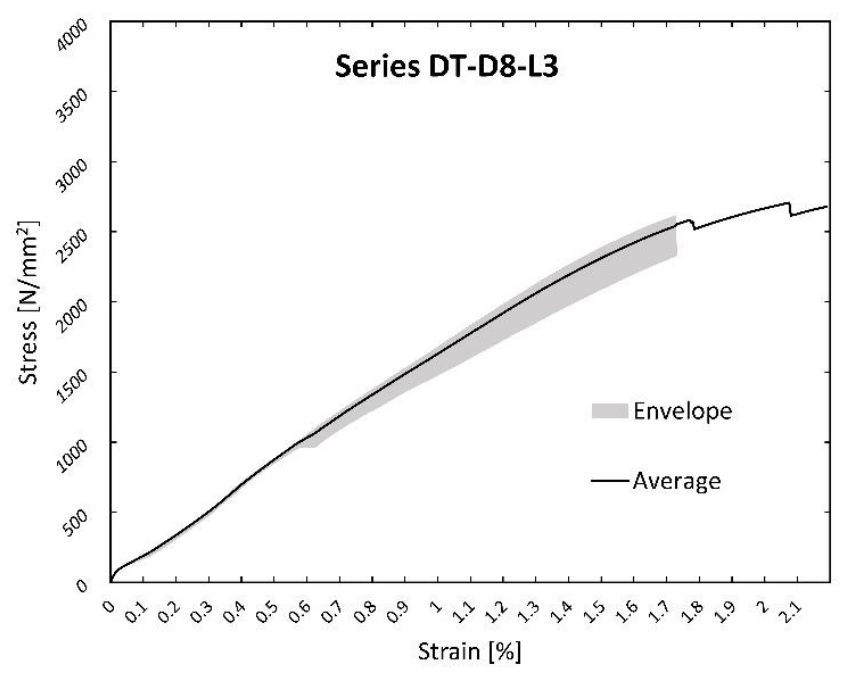

(f)

Figure 2. Envelope stress-strain and average curves for (a) Series DT-D4-L1, (b) Series DT-D8-L1, (c) Series DT-D4-L2, (d) DT-D8-L2, (e) Series DT-D4-L3 Series, and (f) Series DT-D8-L3 


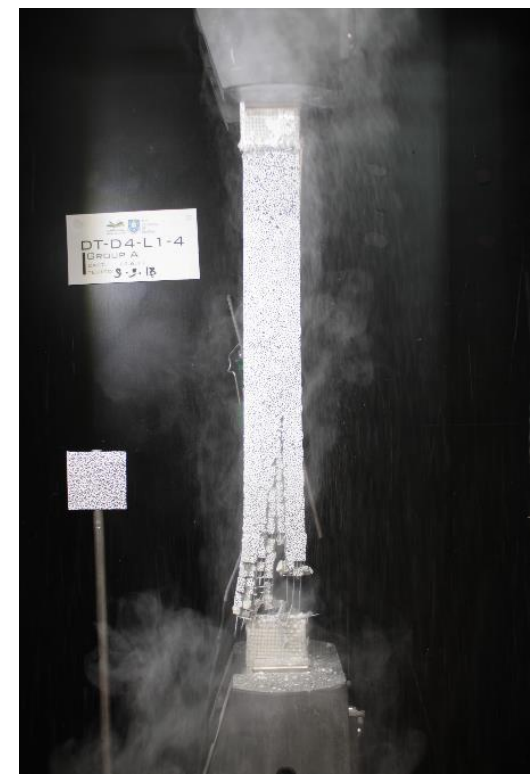

(a)

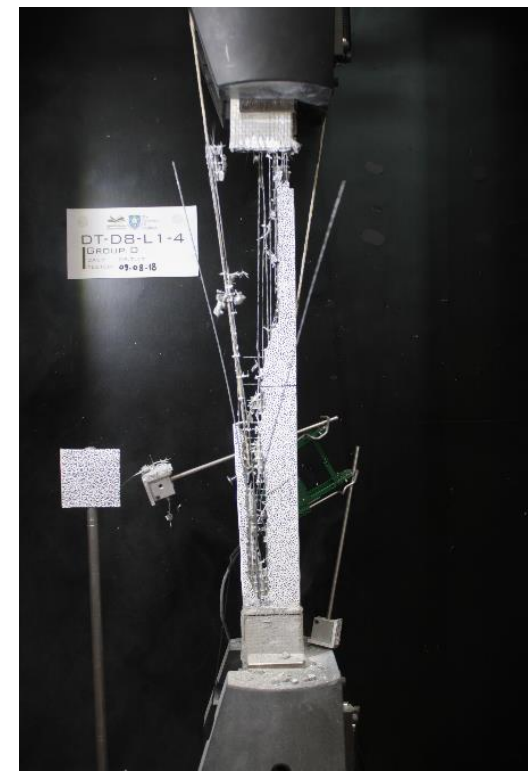

(d)

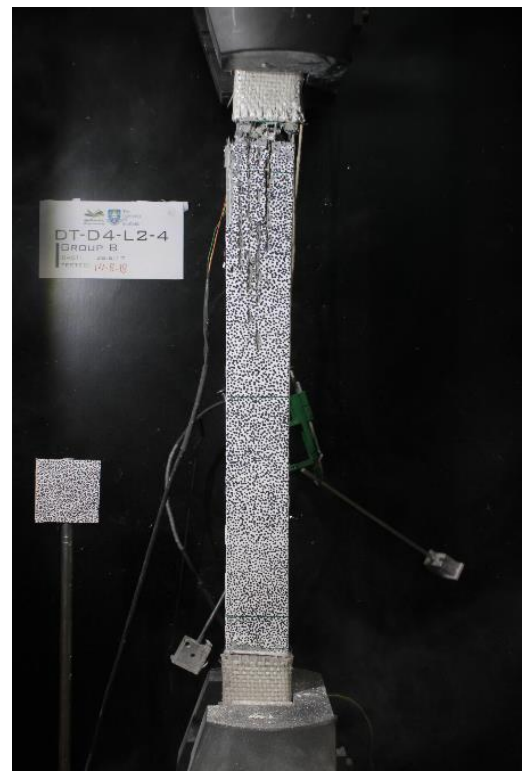

(b)

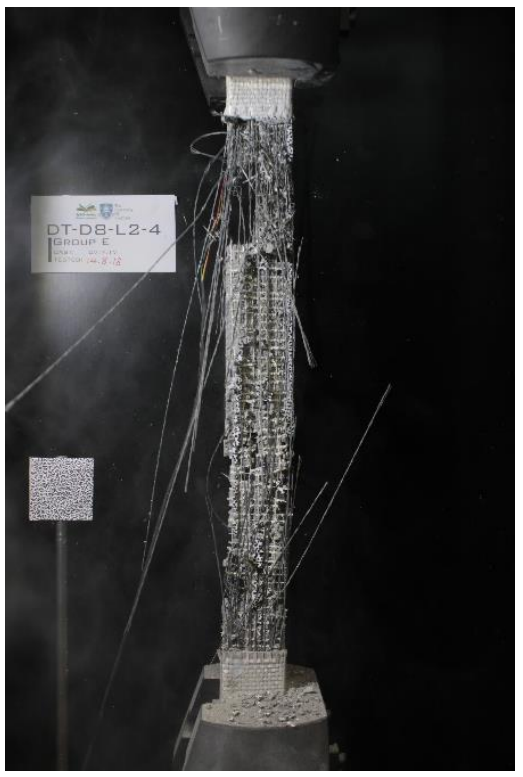

(e)

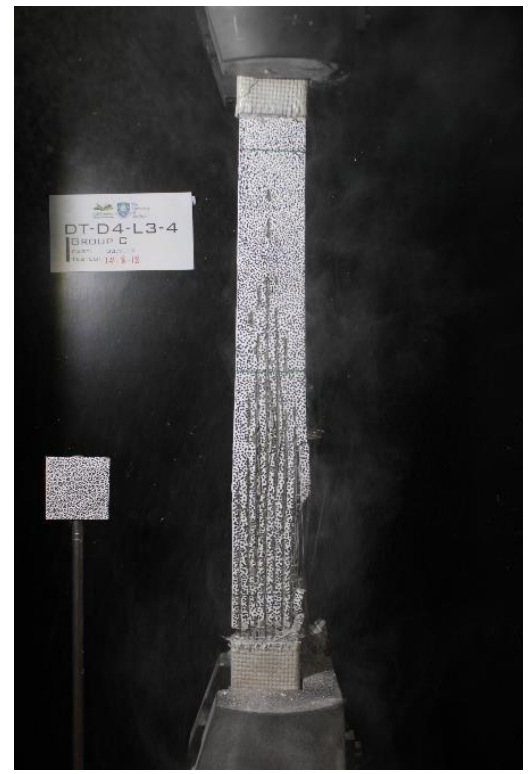

(c)

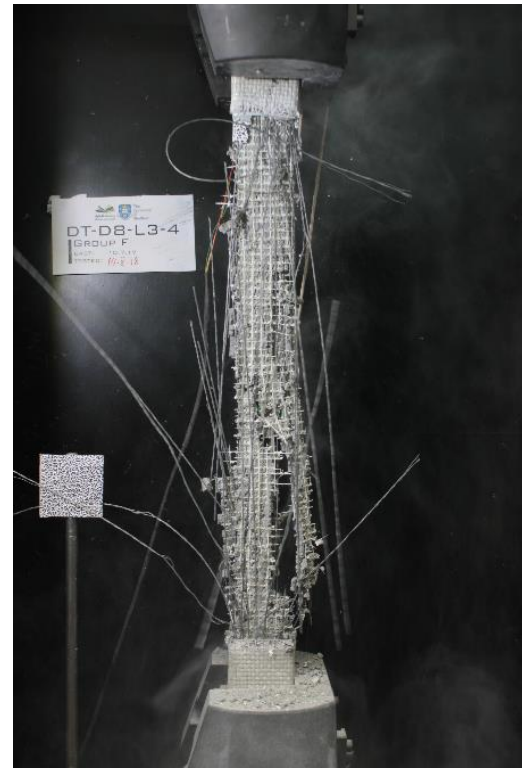

(f)

Figure 3. Failure mode of different specimens from (a) Series DT-D4-L1, (b) Series DT-D4-L2, (c) Series DTD4-L3, (d) Series DT-D8-L1, (e) Series DT-D8-L2, and (f) Series DT-D8-L3

\section{ACKNOWLEDGEMENT}

The materials (steel textiles and cement) for this experiment were provided by Kerakoll S.p.A.. The first author would like to thank the Saudi Arabian Cultural Bureau (UK) and Shaqra University (Saudi Arabia) for sponsoring his $\mathrm{PhD}$ research. 


\section{REFERENCES}

[1] S. De Santis and G. de Felice, Tensile behaviour of mortar-based composites for externally bonded reinforcement systems. Composites Part B: Engineering, 68, 401413, 2015.

[2] S. De Santis and G. de Felice, Steel reinforced grout systems for the strengthening of masonry structures. Composite Structures, 134, 533-548, 2015.

[3] B. Ghiassi, D. V. Oliveira, V. Marques, E. Soares, and H. Maljaee, Multi-level characterization of steel reinforced mortars for strengthening of masonry structures. Materials \& Design, 110, 903-913, 2016.

[4] A. Bilotta, F. Ceroni, E. Nigro, and M. Pecce, Experimental tests on FRCM strengthening systems for tuff masonry elements. Construction and Building Materials, 138, 114-133, 2017.

[5] S. De Santis, F. Ceroni, G. de Felice, M. Fagone, B. Ghiassi, A. Kwiecień, G. P. Lignola, M. Morganti, M. Santandrea, M. R. Valluzzi, and A. Viskovic, Round Robin Test on tensile and bond behaviour of Steel Reinforced Grout systems. Composites Part B: Engineering, 127, 100-120, 2017.

[6] A. Bilotta, F. Ceroni, G. P. Lignola, and A. Prota, Use of DIC technique for investigating the behaviour of FRCM materials for strengthening masonry elements. Composites Part B: Engineering, 129, 251-270, 2017.

[7] T. D'Antino and C. Papanicolaou, Mechanical characterization of textile reinforced inorganic-matrix composites. Composites Part B: Engineering, 127, 78-91, 2017.

[8] G. Thermou, G. de Felice, S. De Santis, S. Alotaibi, F. Roscini, I. Hajirasouliha, M. Guadagnini, Mechanical characterization of multi-ply steel reinforced grout composites for the strengthening of concrete structures. $9^{\text {th }}$ International Conference on FibreReinforced Polymer (FRP) Composites in Civil Engineering (CICE 2018), France, Paris, July 17-19, 2018. 